\title{
Comparing the Analgesic Effects of Lidocaine and Lidocaine with Ketamine in Intravenous Regional Anesthesia on Postoperative Pain
}

\author{
Siamak Yaghubi ${ }^{1}$, Vahideh Rashtchi ${ }^{2,}$, Farzaneh Karamitanha $^{3}$ \\ ${ }^{1}$ Department of Anesthesiology, Medical Faculty, Qazvin University of Medical Sciences, Qazvin, Iran \\ ${ }^{2}$ Department of Anesthesiology, School of Nursing and Midwifery, Zanjan University of Medical Sciences, Zanjan, Iran \\ ${ }^{3}$ Department of Community Medicine, Medical Faculty, Zanjan University of Medical Sciences, Zanjan, Iran
}

Email address:

vrashtchi@gmail.com (V. Rashtchi)

${ }^{*}$ Corresponding author

\section{To cite this article:}

Siamak Yaghubi, Vahideh Rashtchi, Farzaneh Karamitanha. Comparing the Analgesic Effects of Lidocaine and Lidocaine with Ketamine in Intravenous Regional Anesthesia on Postoperative Pain. Journal of Anesthesiology. Vol. 4, No. 1, 2016, pp. 1-4.

doi: $10.11648 /$ j.ja.20160401.11

Received: March 7, 2016; Accepted: April 25, 2016; Published: June 8, 2016

\begin{abstract}
Background and purpose: The main and the most known complication of intravenous regional anesthesia (IVRA) is systemic toxicity due to local anesthetics that occurs following the accidental tourniquet release immediately after injection. This study aims to evaluate the effect of adding ketamine to lower dose of lidocaine on reducing the dose and side effects of lidocaine. Materials and Methods: In this randomized clinical trial, 60 patients undergoing the surgery of upper limb below the elbow under IVRA were randomly divided into two groups. In group 1 (control group), $40 \mathrm{ml}$ lidocaine $0.5 \%$ (200 mg) and in group 2 (intervention group), $40 \mathrm{ml}$ lidocaine $0.25 \%$ (100 mg) plus $40 \mathrm{mg}$ of ketamine $0.1 \%$ injected intravenously. Outcomes included postoperative pain at 15, 30 and 60 minutes after surgery. The pain of the patients was assessed by using the Visual Analogue Scale (VAS Score). Results: Both groups were comparable in demographic and surgical parameters. The average pain based on the VAS score at 15,30 and 60 minutes after surgery was similar in both groups and there was no significant difference between the two groups $(\mathrm{p}>0.05)$. Moreover, postoperative complications including unconsciousness, restlessness, dizziness, nausea, vomiting, tinnitus, seizure, delirium and hallucination had no significant differences ( $\mathrm{p}>0.05)$. Conclusion: Results of this study showed that the addition of ketamine to lower dose of lidocaine in patients receiving IVRA significantly reduced postoperative pain, and reduces the likelihood of systemic toxicity with lidocaine without causing significant adverse effects.
\end{abstract}

Keywords: Regional Anesthesia, Analgesic Effect, Lidocaine, Ketamine

\section{Introduction}

Using general anesthesia for surgery has always had complications such as cardiovascular complications (dangerous arrhythmia), pulmonary complications (possibility of apnea, airway obstruction, aspiration), malignant hyperthermia, and so on. In such cases alternative methods such as regional anesthesia is used. Regional anesthesia includes spinal anesthesia, epidural, peripheral nerves block and intravenous regional anesthesia (IVRA) [1-2].

IVRA, created by August Karl Gustav Bier about 100 years ago, is a simple, safe, and effective technique of providing anesthesia for short surgical procedures on the hand and forearm for an anticipated duration of 60 to 90 minutes [3]. It is an ideal technique for short, procedures on extremities. In the first half of the 20th century, IVRA evolved slowly, but in recent years has advanced quickly [4]. Of the benefits of IVRA, which is feasible for upper and lower limb surgeries, are being easy and fast, having high success rate, fast recovery, controlling the extent of the block and muscle relaxation techniques, availability in open or closed short surgeries. In addition, in this method, the risks of general anesthesia such as apnea, aspiration and cardiovascular complications can be avoided [5-6]. Tourniquet pain and poor postoperative analgesia are 
common problems associated with IVRA [4]. Among the most important complications of this method are sensitivity to local anesthetics, ischemic limb disease, sickle cell crisis, and infection [2].

The most common drug used in this method is regional anesthetics, especially lidocaine [7]. Lidocaine blocks fast voltage-gated sodium channels in the cell membrane of postsynaptic neurons, preventing depolarization and inhibiting the generation of propagation of nerve impulse [8].

Various adjuncts (eg, opioid, nonsteroidal anti-inflammatory drugs, clonidine, dexmedetomidine, ketorolac, dexamethasone, muscle relaxants, neostigmine, ketamine and magnesium) have been tried to hasten the onset, maintain adequate muscle relaxation, reduce tourniquet pain, and increase the duration of analgesia [9], and to reduce the dose of anesthetic drugs to reduce the toxicity [10]. Ketamine is a well-known analgesic drug that acts at least in part as an N-methyl-D-aspartate acid (NMDA) antagonist [11]. It has environmental analgesic properties and increases regional anesthesia duration and anesthesia performance of regional anesthetics [12].

Although randomized double-blind clinical trials have shown the anesthesic effects of ketamine in regional anesthesia in combination with lidocaine, [13-15], we designed this study to evaluate the effect of ketamine when added to lower dose of lidocaine in IVRA.

\section{Method}

This study was a randomized clinical trial in 2013 in Shahid Rajaee Hospital of Qazvin and approved by research ethics committee of Qazvin University of medical science. Written informed consent was provided by all patients. The sample size with $80 \%$ power and $95 \%$ confidence interval based on the reference study [5] was considered as 60 .

Inclusion criteria were ages of 20 to 50 years, American Society of Anesthesiologists Physical Status I or II, and the elective surgery in the upper limb below the elbow. Exclusion criteria were the operation time longer than one hour, history of hypersensitivity to lidocaine, history of peripheral vascular disease, unstable fractures, significant soft tissue injurie, sickle-cell anemia, seizure, cardiac dysrhythmia and psychiatric and neurologic disorders.

Patients were randomly divided into two groups of 30 patients each to receive either $40 \mathrm{ml} \% 0.5$ lidocaine $(200 \mathrm{mg}$ ) (group 1: control group) or $40 \mathrm{ml} \% 0.25$ lidocaine $(100 \mathrm{mg}$ ) plus $40 \mathrm{mg} \% 0.1$ ketamine (group 2: intervention group). In this study, assignment of patients into two groups (control and intervention) implemented using blocked randomization (figure 1).

The day before surgery all patients were briefed about the IVRA and were instructed in how to indicate their pain by using the Visual Analogus Scale (VAS) $(0=$ no pain, $10=$ the most intense pain).

Routine monitorings including pulse oximetry, electrocardiograph, and noninvasive blood pressure measurement were established. Before starting the block, 2 cannulae were placed, one in the dorsum of the operative hand and one in the other hand for drug and crystalloid infusion. 15 minutes before the start of surgery all patients received $2 \mathrm{mg}$ midazolam. The operative arme was elevated for 2 to 3 minutes to complete venous blood drainage and then deprived with an Esmarch bandage. A double-cuffed tourniquet was placed on the operative arm and the proximal cuff was inflated up to $150 \mathrm{~mm} \mathrm{Hg}$ above the patient's systolic blood pressure and the esmarch band was opened. Isolation of blood circulation was confirmed by loss of radial pulse and loss of pulse oximetry tracing from the fingers of the operative hand.

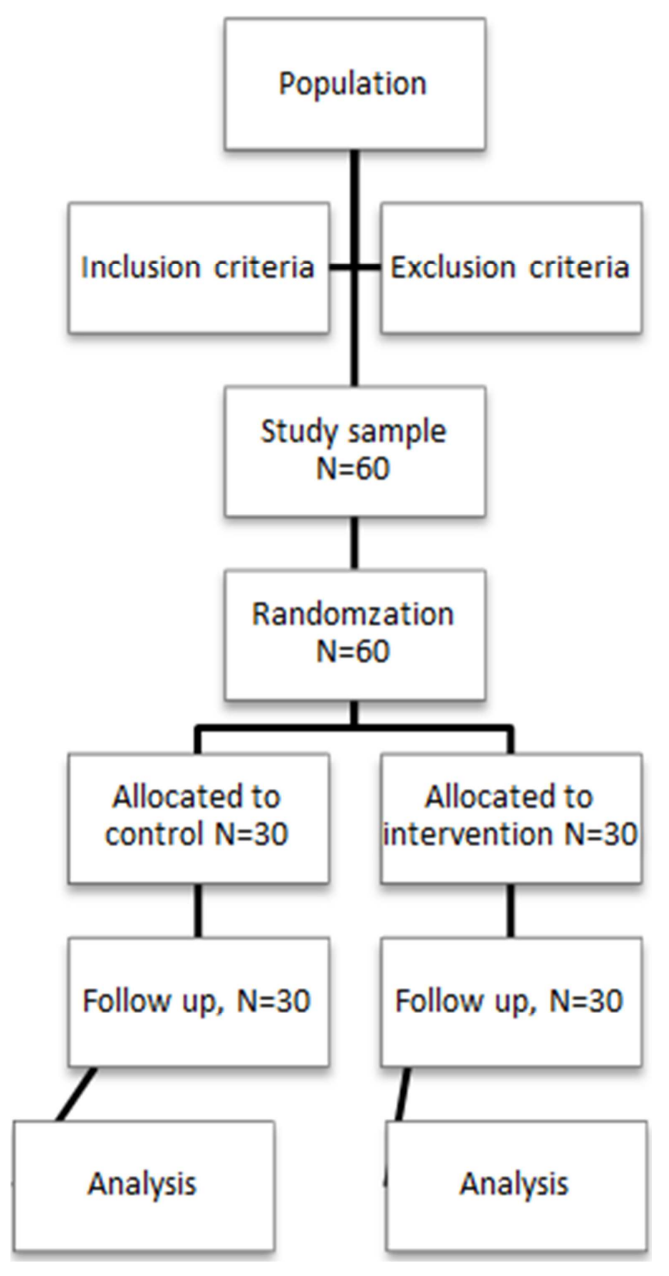

Figure 1. Study flow diagram.

Intravenous regional anesthesia was achieved in group 1 by injecting $40 \mathrm{ml}$ of $\% 0.5$ lidocaine $(200 \mathrm{mg}$ ) and in group 2 by injecting $40 \mathrm{ml}$ of $\% 0.25$ lidocaine plus $40 \mathrm{mg}$ of $\% 0.1$ ketamine through cannulae placed on the dorsum of the related hand over 90 seconds by an anesthesiologist to the injected drugs. After completion of sensory and motor block, approximately 10 minutes after the injection, the distal cuff was inflated up to $250 \mathrm{mmHg}$ and proximal cuff was released and then the operation was started. Oxygen saturation, respiratory rate, heart rate and blood pressure were continuously monitored and any intraoperative adverse effects such as hypoxemia $($ spo $2<\% 92)$, respiratory 
depression (respiratory rate $<10$ beats/min), bradycardia (heart rate $<50$ beats/ $\mathrm{min}$ ) and hypotention (blood pressure $>\% 20$ below the baseline) were recorded and treated. Tourniquet was not deflated before 30 minutes and was not inflated longer than 90 minutes. When the operation completed, deflation of the tourniquet was performed by technique of cyclic deflation. Assessment of pain was made on the basis of the VAS score at 15, 30 and 60 minutes postoperatively. $(0=$ no pain and $10=$ the most intense pain felt by the patient). Any adverse effects in the first 12 hours after surgery including unconsciousness, agitation, dizziness, postoperative nausea and vomiting, tinnitus, seizure, hallucination and delirium in both groups were recorded.

Data were presented as mean $\pm \mathrm{SD}$, numbers, ranges and percentages. To analyze the data, t-test and chi-square were used and $\mathrm{P}$ value $<0.05$ was considered significant.

\section{Results}

Both groups were comparable in demographic and surgical parameters. Age of the patients was $31.80 \pm 10.9$ in the group 1 and $33.63 \pm 10.0$ in the group 2 . There were twenty six $(86.7 \%)$ men in the group 1 and $24(82 \%)$ in the group 2 .

Although there were no statistical differences between the 2 groups in the operation type and time (Table 1 and 2).

Table 1. Comparison of the operation type between the two groups.

\begin{tabular}{lll}
\hline & \multicolumn{2}{l}{ Type of operation } \\
\cline { 2 - 3 } & Fractures & cuts \\
\hline Group 1: Lidocaine & $(30 \%) 9$ & $(70 \%) 21$ \\
Group 2: Lidocaine-Ketamine & $(26.7 \%) 8$ & $(73.3 \%) 22$ \\
P Value $=0.774$ & & \\
\hline
\end{tabular}

There were also no significant differences between the two groups in postoperative complications $(\mathrm{p}>0.05)$ (Table 3$)$.

Table 2. Comparison of the operation time between the two groups.

\begin{tabular}{lll}
\hline & Number & Average (minutes) / SD \\
\hline Group 1: Lidocaine & 30 & $53.83 \pm 18.32$ \\
Group 2: Lidocaine-Ketamine & 30 & $54.00 \pm 17.29$ \\
P. Value $=0.971$ & & \\
\hline
\end{tabular}

Table 3. Frequency of postoperative complications in the two groups.

\begin{tabular}{|c|c|c|c|}
\hline Variable & 1: Lidocaine & 2: Lidocaine-Ketamine & P. Value \\
\hline Unconsciousness & - & - & - \\
\hline Agitation & $1(3.3 \%)$ & $2(6.6 \%)$ & 0.34 \\
\hline Dizziness & $1(3.3 \%)$ & $1(3.3 \%)$ & 0.54 \\
\hline Nausea & $1(3.3 \%)$ & $1(3.3 \%)$ & 0.54 \\
\hline Vomiting & - & $1(3.3 \%)$ & 0.32 \\
\hline Tinnitus & - & - & - \\
\hline $\begin{array}{l}\text { Delirium and } \\
\text { Hallucination }\end{array}$ & - & - & - \\
\hline Seizures & - & - & - \\
\hline
\end{tabular}

According to the results of this study postoperative pain based on VAS scores at 15, 30 and 60 minutes after the operation was similar in both groups and there was no significant differences between the two groups $(p>0.05)$ (Table 4).
Table 4. Postoperative pain profile.

\begin{tabular}{|c|c|c|c|}
\hline Variable $\quad$ Group & 1: Lidocaine & 2: Lidocaine-Ketamine & P. Value \\
\hline minute 15 & $2.40 \pm 2.11$ & $2.96 \pm 2.10$ & 0.303 \\
\hline minute 30 & $4.20 \pm 1.98$ & $3.40 \pm 1.83$ & 0.111 \\
\hline minute 60 & $4.89 \pm 2.11$ & $4.66 \pm 2.15$ & 0.256 \\
\hline
\end{tabular}

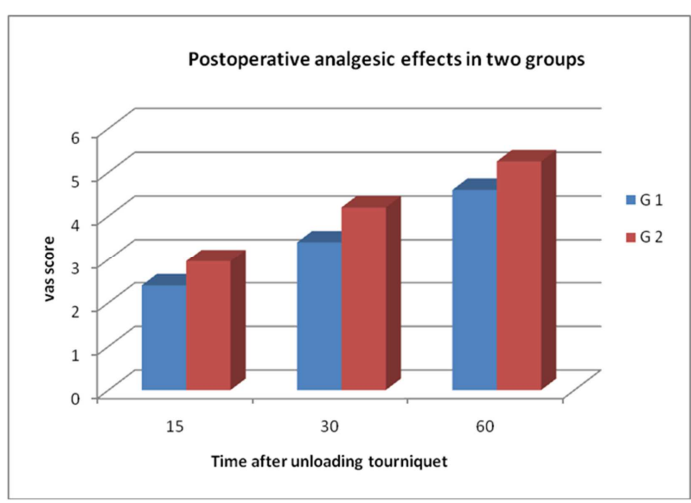

Figure 2. Comparison of two groups.

\section{Discussion}

In this study addition of ketamine to lower dose of lidocaine in patients receiving IVRA reduced the postoperative pain without causing significant side effects.

Lidocaine is the most commonly used drug in IVRA, but because of its central nervous system and cardiovascular complications, it should be used cautiously. The most important complication of lidocaine is systemic toxicity due to accidental deplation of tourniquet after injection, which causes symptoms such as dizziness, tinnitus, unconsciousness and seizure [15-16]; thus, we added ketamine to lower dose of lidocaine in order to reduce these complications.

Practitioners of IVRA now have 4 reasonable adjuvant agents from which to choose. Individual patient characteristics shoud guide the choice of adjuant drug. Patients with poor peripheral vasculature may particularly benefit from the vasodilatory effect of nitroglycerine added to the local anesthetic. Patients with severe ongoing pain or opioid tolerance would be expected to have additional benefit from adjuant clonidine or ketamine, as these drugs are known to be efficacious in these conditions [17]. Ketamine is a noncompetitive antagonist of NMDA which can inhibit the induction of central sensitization owing to peripheral nociceptive stimulation and eliminate hypersensitivity [18]. Durrani et al found that the use of $\% 0.3$ ketamine for regional anesthesia of upper extremities was adequet for complete sympathetic, sensory and motor block. Roy and Deshpande reported similar findings [19].

The pain, based on VAS score at 15, 30 and 60 minutes after surgery was similar in both groups, this rate was lower in the intervention group, but there was no significant and meaningful differences.

In Rahimi's research where he added ketamine $0.1 \mathrm{mg} / \mathrm{kg}$ to $0.5 \%$ lidocaine the result was thus that in lidocaine + ketamine group, tourniquet pain and postoperative pain was 
significantly reduced [20].

In Hall and colleagues study (2014) the effect of adding ketamine to lidocaine in bier block was evaluated and it was shown that this method reduced the need for analgesics during and after surgery without increasing side effects [19].

In Alok and colleagues study (2012) ketamine or Dexmedetomidine was added to lidocaine in IVRA that improved the quality of analgesia without side effects. In this study, ketamine decreased the block beginning time, delay in tourniquet pain, and reduced the need for analgesics after surgery [21].

The most important side effects of ketamine, which limits its administration, are adverse reactions in patients while recovery such as auditory, tactile or visual hallucinations, color emotional perception and a sense of immersion. Benzodiazepines are the most effective drugs to reduce these effects [22-23]. In this study, we used midazolam as premedication in all patients and reduced side effects of ketamine but there was no significant difference in the complications between the two groups.

\section{Conclusion}

According to the results of our study, we considered that adding ketamine to lower dose of lidocaine for IVRA is a safe method and thus applicable for surgeries in the upper exterimities below the elbow that lead to acceptable pain relief without causing significant adverse effects.

Finally, we concluded that use of adjutants acting synergically with the local anesthetics have improved the safety and efficiency of IVRA.

\section{References}

[1] Wedel DJ, Hor Locker TT. Nerve block. In: Miller RD, editors. Miller's Anesthesia. $7^{\text {th }}$ ed. Philadelphia Churchill Livingstone; 2010. 1648-9.

[2] Charls B, Berde \& Gary R. Strichartz, Local anesthetics. In: Miller RD, editors. Miller's Anesthesia. $7^{\text {th }}$ ed. Philadelphia: Churchill Livingstone; 2010. 2436.

[3] Brown EM, Mc Griff, Malinowski RW. Intravenous regional anesthesia (Bier block): Review of 20 years experience. Can J Anaesth. 1989; 36: 307-310.

[4] Johnson CN. Intravenous regional anesthesia: new approaches to an old technique. CRNA. 2000; 11: 57-61

[5] Tverskoy M, Oren M, Vaskovich M, et al. Ketamine enhances local anesthetic and analgesic effects of bupivacaine by peripheral mechanism: A study in postoperative patients. Neurosci Lett 1996; 215: 5- 8.

[6] Carlton SM, Hargett Gl, Coggeshall RE. Localization and activation of glutamate receptors in unmyelinated axons of rat glabrous skin. Neurosci Lett 1995; 197: 25- 8.

[7] Pedersen JL, Galle TS, Kehlet H. Peripheral analgesic effects of ketamine in acute inflammatory pain. Anesthesiology 1998; 89: $58-66$
[8] Marcia L., Buck, Pharm. D. Use of lidocaine for analgesia in children and adolescents. Pediatr Pharm. 2013; 19 (12).

[9] Flamer D, Peng PW. Intravenous regional anesthesia: a review of common local anesthetic options and the use of opioids and muscle relaxants as adjuncts. Local Reg Anesth. 2011; 4: 57-76.

[10] Gorgias NK, Maidatsi PG, Kyriakidis AM, et al. Clonidine versus ketamine to prevent tourniquet pain during intravenous regional anesthesia with lidocaine. Regional Anesthesia and Pain Medicine 2001 Nov- Dec; 26 (6): 512-7.

[11] Annetta MG, Iemma D, Garisto C, Tafani C, Proietti R. Ketamine: new indications for an old drug. Curr Drug Targets. 2005; 6: 789-794.

[12] Gunduz M, Ozalevli M, Ozbek H, Ozcengiz D. Comparison of caudal ketamine with administration for postoperative analgesia of hypospadias surgery in children. Pediatric Anesthesia 2006; 16: 158-63.

[13] Durrani Z, Winnie AP, Zsigmond EK, et al. Ketamine for intravenous regional anesthesia. Anesthesia \& Analgesia 1989; 68: $328-32$.

[14] Attal N, Rouaud J, Brasseur L, Chauvin M, Bouhassira D. Systemic lidocaine in pain due to peripheral nerve injury and predictors of response. Neurology. 2004 Jan 27; 62 (2): 218-25.

[15] Sen S, Ugur B, Aydın ON, Ogurlu M, Gursoy F, Savk O. The analgesic effect of nitroglycerin added to lidocaine on intravenous regional anesthesia. Anesth Analg 2006; 102: 916-20.

[16] Reves JG, Class PS, Lubarsky DA, et al. Intravenous anesthetics. Miller RD, editors. Miller's Anesthesia. 7th ed. Philadelphia: Churchill Livingstone; 2010. 747-92.

[17] Flood P. Personalized intravenous regional anesthesia. Saudi J Anaesth. 2010; 4: 46.

[18] Liu HT, Hollmann MW, Liu WH, Hoenemann CW, Durieux ME. Modulation of NMDA receptor function by ketamine and magnesium: part I. Anesth Analg. 2001; 92: 1173-1181.

[19] Hala S. Abdel-Ghaffar, MD, Mahmoud Abdel-Azez Kalefa, $\mathrm{PhD}$, Ahmed Said Imbaby, MBBCH. Efficacy of ketamine as an adjunct to lidocaine in intravenous regional anesthesia. Regional Anesthesia and Pain Medicine. 2014; 39: 418-422.

[20] Rahimi M, Saghaei M, Heidari M., Intravenous regional anesthesia using lidocaine and ketamine, EJA 2006; 23: 127-129.

[21] Alok Kumar, DK Sharma, Barun Datta. Addition of ketamine or dexmedetomedian to lingocaine in intravenous regional anesthesia: A randomized controlled study. Journal of Anaesthesiology Clinical Pharmacology 2012; 28 (4): 501-4.

[22] Baad-Hansen, L., Juhl, GI., Jensen, TS., Brandsborg, B., \& Svensson, P. Differential effect of intravenous S-ketamine and fentanyl on atypical odontalgia and capsaicin-evoked pain, Pain, 2007; 129 (1-2): 46-54

[23] Amr, YM. Multi-Day Low Dose Ketamine Infusion as Adjuvant to Oral Gabapentin in Spinal Cord Injury Related Chronic Pain: A Prospective, Randomized, Double Blind Trial, Pain Physician, 2010; 13: 245-49. 